\title{
Supply chain relationships between first and second tier suppliers in South African automotive supply chains: A focus on trust
}

\begin{abstract}
Authors:
Aletta S. Tolmay

Johanna A. Badenhorst-Weiss ${ }^{1}$

Affiliations:

${ }^{1}$ Department of Business

Management, University of

South Africa, South Africa

Correspondence to:

Hannie Badenhorst-Weiss

Email:

badenja@unisa.ac.za

Postal address:

PO Box 392, University of

South Africa 0003,

South Africa

Dates:

Received: 23 July 2015

Accepted: 25 Aug. 2015

Published: 30 Oct. 2015

How to cite this article:

Tolmay, A.S. \& Badenhorst-

Weiss, J.A., 2015, 'Supply

chain relationships between

first and second tier

suppliers in South African

automotive supply chains:

A focus on trust', Journal of

Transport and Supply Chain

Management 9(1), Art.

\#205, 8 pages. http://dx.doi.

org/10.4102/jtscm.v9i1.205

\section{Note:}

This article makes a contribution to provide more insight into collaborative relationships between first and second tier suppliers in automotive supply chains in South Africa. Most of previous studies focused on relationships between automotive assemblers and their first tier suppliers.
\end{abstract}

\section{Read online:}

Background: The automotive industry is characterised by a network of long term collaborative agreements between component suppliers and assemblers. For collaboration to be successful trust between the supply chain partners is vital. Although many variables influence the efficiency of collaborative relationships, the human behaviour issues related to culture and trust are often much more difficult to solve. Trust is singled out in this article as a contributor to value in the supply chain relationships. Increased trust leads to more confidence resulting in better collaboration.

Objectives: The purpose of the study was to explore collaborative relationships between first and second tier suppliers (component manufacturers) in automotive supply chains in South Africa and the role of trust in the relationship value.

Method: This quantitative study had been conducted amongst members of the National Association for Automobile Component and Allied Manufacturers of South Africa (NAACAM), who are suppliers to the large automotive assemblers. The research utilised closed ended questions to obtain the perceptions of managers in automotive component manufacture regarding trust and relationship value with their best suppliers.

Results: With a linear regression model it was found that there is a high degree of trust in the collaborative relationships between first and second tier suppliers of components in the automotive industry in South Africa.

Conclusion: The automotive industry is one of the most successful industries in South Africa. They compete globally and apply best practices, particularly those in supply chain management. The industry is characterised by networks of collaborative relationships on different levels. These relationships seem to be successful as they are based on trust.

\section{Introduction}

'Trust is the chicken soup of social life' (Uslaner 2002:1). Trust is highly valued at a personal and professional level in society as low levels of trust lead to high levels of corruption (Uslaner 2013:3605). With soaring corruption levels worldwide, and in South Africa in particular, the question remains if one can trust anybody in business today.

The supply chain management approach is based on the cooperation and collaboration of members in a supply chain. For collaboration to be successful trust between the supply chain partners is vital. Although many variables such as technology compatibility, information exchange and appropriate measurement systems influence the efficiency and effectiveness of collaborative relationships, the human behaviour issues related to culture and trust are often far more difficult to solve (Bowersox et al. 2012:353). Trust is singled out in this article as a contributor to value in the supply chain relationships. Increased trust leads to more confidence resulting in better collaboration (Ambe 2014:47).

South Africa's most important manufacturing sector, the automotive industry, follows the supply chain approach to the fullest extent (Ambe \& Badenhorst-Weiss 2011:337; Tolmay 2012:19). The industry consists of a network, of many layers or tiers, of suppliers who supply components and modules to automotive assemblers (such as Toyota, Ford, etc.). This industry is characterised by a network of long term collaborative agreements (Ambe 2014:47). This article reflects on a study that had been conducted to analyse the collaborative relationship value between supply chain role players, particularly between first and second tier suppliers, in the South African automotive supply chain.

Copyright: (c) 2015. The Authors. Licensee: AOSIS OpenJournals. This work is licensed under the Creative Commons Attribution License. 
Prior studies of the automotive supply chains concentrated on the relationship between automotive assemblers, also known as 'original equipment manufacturers' (OEMs), and their first tier suppliers (Ambe 2014:47-61; Naude \& Badenhorst-Weiss 2012:91-106). This research focuses on the relationships between first and second tier suppliers, and particularly the role of trust in these relationships. Although it was found that trust plays a crucial role in long term collaborative relationships, there is still a need for research to form more robust theoretical conclusions regarding trust (Akrout \& Akrout 2011:9; Vieira et al. 2013:274). In addition, literature models depicting the role of trust within the automotive supply chain remains limited (Theron, Terblanche \& Boshoff 2011:190; Tolmay 2012:155). For successful supply chain management to occur in the South African automotive industry, collaboration and trust between first and second tier suppliers is necessary, although this might be challenging because many first tier suppliers are large international or multinational companies and second tier suppliers are usually of local descent (Tolmay 2012:2).

This paper reports on research which explored the collaborative relationship between first and second tier suppliers (component manufacturers) in automotive supply chains in South Africa, and the role of trust in the relationship value. The research question is, therefore: Is there a directional correlation between trust and relationship value in the South African automotive component supply chain?

This article will start with an exploration of literature sources of the automotive industry to contextualise the study, followed by an exploration of the topic of buyer-supplier relationships in supply chains. Further, the concept of trust and the role of trust in the buyer-supplier relationship are explored. The research methodology applied in the study will then be outlined. Finally, the analysis, findings and recommendations will be presented.

\section{Literature review}

\section{The automotive industry}

The automotive industry is a truly global industry. Major automotive manufacturing regions include the North American Free Trade Area (NAFTA), western Europe, Japan, Asia-Pacific, eastern Europe, South America and South Africa (AIEC 2014:7). The South African automotive industry is aligned to the global automotive industry and is, therefore, part of the global supply chains. The automotive industry in South Africa is concentrated in three of the country's nine provinces, namely Gauteng, the Eastern Cape and KwaZulu-Natal, and in close proximity to its suppliers' (AIEC 2014:9; Tolmay 2012:16). However, some automotive industry development is also taking place in the Western Cape and North West provinces (Tolmay 2012:16).

The automotive industry is the largest manufacturing sector in South Africa (AIEC 2014:4; Lamprecht, RudanskyKloppers \& Strydom 2011). The South African manufacturing output accounts for $15 \%$ of the country's gross domestic product (GDP) and the automotive industry accounts for about 30\% of manufacturing output (AIEC 2014:6). Exports of automotive components and vehicles contribute substantially to the South African trade balance. For example in 2013 the South African automotive industry exported 276378 completely built-up vehicles to 87 destinations (AIEC 2014:46). Passenger car exports, as a percentage of passenger car production, totalled $57.3 \%$ (Table 1 ) and light commercial vehicles (LCVs), as a percentage of LCV production, totalled $48.8 \%$ in 2013 (Table 1). As a result, the exports of the South African automotive industry impacted positively on the trade balance.

The automotive industry in South Africa is made up of complete supply chains with seven OEMs, namely BMW, Ford, Nissan, Volkswagen, General Motors, Toyota and Mercedes Benz, as the biggest and most powerful parties in the supply chain (AIEC 2014:5). The OEMs source modules from a network of first tier (Tier 1) suppliers, who in turn source smaller components from second tier (Tier 2) suppliers. The industry also incorporates aftermarket components which are defined as role players after a vehicle has left the factory floor, such as dealers, fuel stations, and panel beaters (Tolmay 2012:xvi). South Africa has approximately 4600 fuel-service stations and 1898 specialist repairers. In addition, the industry includes the following:

- 1374 new car dealerships

- 1696 used vehicle outlets

- 1508 specialist tyre dealers and retreaders

- 483 engine reconditioners

- 167 vehicle body builders

- 2907 parts dealers

- around 220 farm vehicle and equipment suppliers (AIEC 2014:87).

TABLE 1: Export statistics of passenger cars and light commercial vehicles.

\begin{tabular}{|c|c|c|c|c|c|c|c|c|}
\hline \multirow[t]{3}{*}{ Year } & \multicolumn{4}{|c|}{ Passenger cars } & \multicolumn{4}{|c|}{ Light commercial vehicles } \\
\hline & \multicolumn{2}{|c|}{ Market } & \multirow[t]{2}{*}{ Total } & \multirow{2}{*}{$\begin{array}{c}\text { Exports as a \% of } \\
\text { total }\end{array}$} & \multicolumn{2}{|c|}{ Market } & \multirow[t]{2}{*}{ Total } & \multirow{2}{*}{$\begin{array}{c}\text { Exports as a } \% \text { of } \\
\text { total }\end{array}$} \\
\hline & Domestic & Exports & & & Domestic & Export & & \\
\hline 2010 & 113740 & 181654 & 295394 & 61.5 & 96823 & 56950 & 153773 & 37.0 \\
\hline 2011 & 124736 & 187529 & 312265 & 60.1 & 108704 & 84125 & 192819 & 43.6 \\
\hline 2012 & 120417 & 151659 & 272076 & 55.7 & 121638 & 123443 & 245081 & 50.6 \\
\hline 2013 & 113364 & 151893 & 265257 & 57.3 & 127188 & 121345 & 248533 & 48.8 \\
\hline $2014 \dagger$ & 110000 & 160000 & 270000 & 59.3 & 127000 & 160000 & 287000 & 55.7 \\
\hline
\end{tabular}

Source: AIEC, 2014, Automotive export manual 2014. Zest (Pty) Ltd., Pretoria

$\dagger$, estimated. 
It was mentioned above that the South African automotive industry is part of the global supply chains. There is a general consensus in literature that globalisation brings about numerous challenges for supply chains and, thus, also for local automotive supply chains. These challenges include shorter life cycles of products, cost reduction pressures and more demanding, knowledgeable and sophisticated customers with rapidly changing buying patterns. (Ambe \& Badenhorst-Weiss 2011:352; Tolmay 2012:57). In addition, the South African automotive industry, and especially the component suppliers, is faced with competition from low cost manufacturing countries (Barnes \& Black 2013:18; Lamprecht et al. 2011:56). On top of this, customers are reducing their number of suppliers - a process called supplier rationalisation - to, amongst others, manage the supply chain more effectively (Ambe \& Badenhorst-Weiss 2013:2).

There is also consensus in literature that the strategic success of supply chain management is based on the strengths of relationships in supply chains (Thomas \& Skinner 2010:44). It is consequently crucial for automotive supply chain role players to optimise supply chain effectiveness in every sense and to ensure that value is added in every process through collaborative relationships.

\section{Supply chain management}

In its bare essence a supply chain is a series of close relationships amongst multiple firms (Thomas \& Skinner 2010:44). Supply chain management is defined by the Council of Supply Chain Management Professionals (CSCMP) as:

The planning and management of activities involved in sourcing and procurement, conversion, and al logistics management activities. Importantly, it also includes coordination and collaboration with channel partners, which can be suppliers, intermediaries, third party service providers and customers. (CSCMP 2015:n.p.)

Consequently, supply chain management encompasses the management of upstream and downstream suppliers with the aim of adding more value than the competition and of achieving a competitive advantage (Ambe \& BadenhorstWeiss 2013:8). Automotive supply chains revolve mainly around operational efficiency and supplier collaboration. The successful management of suppliers provides a competitive advantage in automotive supply chains and is depicted by strategic partnerships, collaborative buyer-supplier relationships, cooperative operations and product design, trust and the sharing of information as well as risk (Ambe 2014:50-51).

\section{Supply chain relationships}

Increased global competition is forcing companies to add more value to their products or services, and one of the ways to achieve this is to form long term collaborative relationships between customers and suppliers (Saban \& Luchs 2011:43). According to Wisner, Tan and Leong (2016:528) collaboration means 'working together through information sharing with suppliers and customers on various activities'.

Not all relationships between suppliers and buyers in supply chains will be collaborative or of a partnership type, but will depend on the situation and the nature of the product or service. For standard, routine and bottleneck products and services the buyer-supplier relationship will be adversarial or arm's length, as the buyers use multiple sourcing techniques. When buyers and suppliers accept that they have mutual goals they are taking a step closer to collaboration. 'The emergence of collaborative relationships among firms in the supply chain is the recognition of mutual dependence' (Bowersox et al. 2012:352). When more critical, strategic products and services are required suppliers and buying organisations often need to work together from product development and process design through to routine deliveries. The relationship will determine the degree of interaction, information sharing and collaboration between buyers and suppliers. With collaborative relationships, particularly when these have developed to a full partnership (Swink et al. 2011:294-295), also called a strategic alliance (Bowersox et al. 2012:353; Wisner et al. 2016:119), the buyers and suppliers (partners) expect to create better solutions than they could create alone. Partners plan together and have full access to information, designs, schedules, cost data. 'A distinguishing feature of such relationships is the expectation that the collaboration will be continuous' (Bowersox et al. 2012:353). Often in this kind of relationship long term contracts formalise the relationship. 'Partnerships foster long term loyalty and mutual respect, ultimately leading to many of the advantages of vertical integration' (Swink et al. 2011:295).

There is ample evidence of collaborative, partnership type buyer-supplier relationships in automotive supply chains. Swink et al. (2011:295-295) mention examples at the Ford Motor Company in Brazil, as well as at Toyota and Honda. Wisner et al. (2016:78) refers to the strategic partnership between Jaguar Land Rover and a key supplier, Gobel and Partner. The South African automotive supply chain is also characterised by long term collaborative relationships between customers and suppliers (Ambe 2014:50).

\section{Trust}

Trust is critical for any partnership or alliance to work (Wisner et al. 2016:79). Trust is a multifaceted concept and mostly conceived as the rational response to trustworthy behaviour by others (Uslaner 2002:6). Trust was defined by various authors in similar ways to the Oxford Dictionary's definition, namely the 'Firm belief in the reliability, truth, or ability of someone or something'. Akrout and Akrout (2011:4) noted three different dimensions in trust theory. Firstly, a one-dimensional conception entails the conceptualisation and definition of trust by authors such as Morgan and Hunt (1994:20-38) and Geykens and Steenkamp (1995:351-371). They attempted to define and model the complexity of trust, but settled for a more holistic approach. Secondly, the 
two-dimensional conception of trust refers to the motives and intentions of the two parties with relation to trust, such as the benefits that they can both gain. Thirdly, the thirddimension of trust relates to the ethical standards or honest outcomes as that both parties believe the other will honour an agreement (Akrout \& Akrout 2011:4).

\section{Trust in collaborative relationships in supply chains}

In collaborative buyer-supplier relationship the partners must trust each other - 'no real collaboration can exist in supply chain relationships without meaningful trust' (Bowersox et al. 2012:353). Thus, trust can enhance the value of collaborative relationships (Saban \& Luchs 2011:42).

In addition to Akrout and Akrout's (2011:4) dimensions of trust, Bowersox et al. (2012:353-354) distinguish between reliability-based trust and character-based trust. Reliabilitybased trust refers to the willingness and ability of a supply chain partner to perform as expected and promised. Character-based trust (in line with Akrout \& Akrout's second and third dimensions) is based in an organisation's culture and philosophy. It stems from the perceptions that supply chain parties (buyers and suppliers) have about their partners' intentions to seek the best interest for everybody and consider the impact of their actions on other partners in the supply chain. 'Trusting partners believe that each will protect the other's interest' (Bowersox et al. 2012:354). Reliability-based trust is necessary for the formation of collaborative relationships in the supply chain, but this is not the only condition. To maintain the relationship over the long term it should be a character-based relationship.

A study specifically undertaken on the automotive industry by Sako (2006:267-294) and later confirmed by Saban and Luchs (2011:46), found that trust in the supply chain results in a higher degree of learning and continuous improvements coupled with the advantage of cost reduction. Gounaris (2005:17) stated that 'The more the customer trusts the supplier, the higher the perceived value of the relationship'. In line with Gounaris (2005) various authors agree on the advantages of trust in supply chain collaborative relationships. These advantages include: competitive advantage, satisfaction, commitment, business retention, innovation, better supplier performance, sustainability, information and knowledge sharing, improved supply chain relationships, customer satisfaction and commitment, as depicted in Table 2 .
Further to the numerous advantages, Drake and Schlachter (2008:851-864), and later Thomas and Skinner (2010:46), stated that trust mitigates risk. Trust can also reduce general production and operation costs (Çerri 2012; Drake \& Schlachter 2008; Thomas \& Skinner 2010; Tolmay 2012), procurement costs (Saban \& Luchs 2011) and transaction costs (Akrout \& Akrout 2011; Çerri 2012). As a result, trust plays a critical role in the supply chain.

It was further found that higher levels of trust in the automotive industry result in a trust centric approach with suppliers rather than a command and control approach (Saban \& Luchs 2011:52). A command and control approach, usually applicable to a transactional collaboration, constantly monitors the performance of the supplier at a high cost with low value exchanges between the two parties. The customer can easily dissolve the partnership and find a new source. In contrast, the trust centric approach between customer and supplier shares a high degree of strategic collaboration through interaction, knowledge and innovation sharing, and the parties are willing to invest in each other by means of time and energy to secure successful long term exchange (Saban \& Luchs 2011:52).

When the relational exchange complexity increases, it is essential to simultaneously increase the trust centric collaboration. Strategic collaboration is required when partners share physical and intellectual assets. This is achieved when parties share a trust relationship which is not defined by contracts but rather by personal contribution (Saban \& Luchs 2011:51).

Trust develops over time and repeated interactions amongst organisations and '... goodwill develops over time between partners' (Wisner et al. 2016:80). Trust is elusive, but it tends to grow when both the supplier and buyer benefit (Swink et al. 2011:295).

It seems that factors such as culture and the resistance to complete transparency are hindrances to a trusting relationship. Ambe (2014:48) notes that automotive manufacturers differ culturally from each other and this is also eminent in different supply chain strategies. One of the largest hurdles hindering collaboration is a lack of trust over complete information sharing between supply chain partners (Jacobs, Chase \& Aquilano 2009:499).

TABLE 2: Trust in the supply chain.

\begin{tabular}{|c|c|c|c|c|c|c|c|c|c|c|}
\hline $\begin{array}{l}\text { Trust advantages } \\
\text { in the supply chain } \\
\text { partnerships }\end{array}$ & $\begin{array}{l}\text { (Ambe } \\
\text { 2014) }\end{array}$ & $\begin{array}{l}\text { (Vieira } \\
\text { et al. 2013) }\end{array}$ & $\begin{array}{l}\text { (Tolmay } \\
\text { 2012) }\end{array}$ & $\begin{array}{l}\text { (Çerri } \\
\text { 2012) }\end{array}$ & $\begin{array}{l}\text { (Li et al. } \\
\text { 2012) }\end{array}$ & $\begin{array}{c}\text { (Ebrahim-Khanjari, } \\
\text { Hopp \& Iravani } \\
\text { 2012) } \\
\end{array}$ & $\begin{array}{l}\text { (Saban \& } \\
\text { Luchs 2011) }\end{array}$ & $\begin{array}{c}\text { (Akrout \& } \\
\text { Akrout 2011) }\end{array}$ & $\begin{array}{c}\text { (Thomas \& } \\
\text { Skinner 2010) }\end{array}$ & $\begin{array}{c}\text { (Drake \& } \\
\text { Schlachter } \\
\text { 2008) } \\
\end{array}$ \\
\hline Innovation & $x$ & $x$ & $x$ & - & - & - & $x$ & - & $x$ & - \\
\hline Supplier performance & $x$ & & & - & - & $x$ & $x$ & $x$ & $x$ & $x$ \\
\hline Sustainability & - & - & $x$ & - & - & $x$ & - & - & $x$ & $x$ \\
\hline $\begin{array}{l}\text { Information and } \\
\text { knowledge sharing }\end{array}$ & $x$ & & $x$ & - & - & $x$ & $x$ & - & $x$ & - \\
\hline Customer satisfaction & - & - & $x$ & $x$ & - & - & $x$ & $x$ & - & $x$ \\
\hline Commitment & - & $\mathrm{x}$ & $x$ & - & $\mathrm{x}$ & - & $x$ & - & - & $x$ \\
\hline
\end{tabular}

Note: Please see the full reference list of the article, Tolmay, A.S. \& Badenhorst-Weiss, J.A., 'Supply chain relationships between first and second tier suppliers in South African automotive supply chains: A focus on trust', Journal of Transport and Supply Chain Management 9(1), Art. \#205, 8 pages. http://dx.doi.org/10.4102/jtscm.v9i1.205, for more information. 
With the current unstable economic environment, it is crucial for all automotive component stakeholders to capitalise on best practices in order to survive. Therefore, all avenues should be pursued to improve trust relationships in supply chains. Unfortunately, an empirical study by Fawcett, Magnan and Williams (2004) and later on by Drake and Schlachter (2008:852) stated that many supply chain relationships still lack significant trust between the parties involved.

It became clear from the literature that trust is one of the most important dimensions of or contributors to effective and efficient collaborative supply chain relationships. As indicated previously, this article reports on a study that had been conducted to determine if there is trust in collaborative relationships between first and second tier suppliers (component manufacturers) in the South African automotive supply chains. Consequently, 'trust' and 'relationship value' were included in the questionnaire in order to determine their existence within the automotive supply chain. As per theory, trust is identified as a strong predictor of relationship value which corresponds with the theory presented by Morgan and Hunt (1994) - but, is this also true in the South African automotive supply chain?

\section{Empirical study Background and methodology}

The study has been conducted amongst members of the National Association for Automobile Component and Allied Manufacturers of South Africa (NAACAM). NAACAM members are suppliers to the large automotive assemblers or OEMS (Toyota and others).

This quantitative research study utilised a questionnaire with structured close ended questions based on the research of Eggert, Ulaga and Schultz (2006), as well as Morgan and Hunt (1994). In preparation for the research, a questionnaire validation process was introduced where qualitative questions were posed to four industry experts in order to ensure that all valid information related to the South African automotive industry was included in the questionnaire. The research utilised six closed ended questions in the questionnaire in order to obtain the perceptions of managers of the automotive component manufacturers (Tier 1 suppliers), regarding trust and relationship value, with regards to their best suppliers as per Table 3. A bipolar seven point semantic differential scale was utilised with respondents having to choose their perception on a statement from 'strongly disagree' to 'strongly agree'.
The questionnaires were sent via email and were specifically addressed to managers, including the chief executive officer, production manager and procurement manager of component manufacturers who are members of NAACAM. Non-respondents were phoned and telephonic interviews conducted. NAACAM, established, in 1980, has 140 members and represents the interests of the South African automotive component manufacturers who are the suppliers to automotive assemblers. Almost 70\% of South Africa's first tier (Tier 1) component manufacturers are NAACAM members (AIEC 2015:7). The questionnaire was sent to all the NAACAM members who represent the whole population. Of the potential 140 participants for the survey, 114 respondents participated. Hence, a response rate of $81.4 \%$ was achieved. However, not all respondents answered all of the questions. The questionnaires returned by the respondents were cleaned and captured using SPSS. The findings are presented below.

\section{Profile of respondents}

The research achieved a representative response spread according to the demographical information obtained $(n=106)$. A total of $47(44.3 \%)$ respondents indicated that they constitute an international shareholding structure, 31 (29.2\%) indicated a local shareholding and 28 (26.4\%) indicated a mixture of local and international shareholding.

Of the 101 respondents who disclosed their annual turnover 54 (53.5\%) indicated that they earn more than R200 million. Twenty five $(24.7 \%)$ respondents indicated an annual turnover of between R50 million and R200 million, 17 (16.8\%) indicated a turnover of R5 million to R50 million, and five (5\%) of respondents indicated a turnover of less than R50 million. The above indicates that first tier (Tier 1) suppliers (component manufacturers) are large organisations and are usually of international descent.

Corresponding to the turnover of the company, 55 automotive component suppliers indicated that they employ a workforce of more than 200 employees. Forty (37.4\%) respondents employ between 51 and 200 workers, 10 employ between 21 and 50, and two respondents have less than 20 employees.

The South African automotive industry consists of four automotive clusters of different sizes in different provinces. They are, in order of size, situated in Gauteng, the Eastern Cape, KZN, and the Western Cape. The response received in this study corresponds to the size of the clusters. Forty nine $(46.7 \%)$ respondents were from the Gauteng Automotive Cluster, 43 (32.4\%) were from the Eastern Cape, 10 (9.5\%)

TABLE 3: Questions relating to trust and relationship value.

\begin{tabular}{ll}
\hline Factor & Questions \\
\hline Trust & In our relationship, my firm feels that Supplier A can be counted on to do what is right \\
& In our relationship with Supplier A, our firm feels that Supplier A can be trusted \\
& In our relationship, Supplier A demonstrates a high level of integrity \\
Relationship Value & Our organisation gains value from the relationship with Supplier A \\
& When comparing all costs and benefits involved in our relationship with Supplier A, my firm feels that Supplier A creates value for us \\
& The relationship my firm has with Supplier A is valuable to us \\
\hline
\end{tabular}


TABLE 4: Profile of respondents.

\begin{tabular}{llcc}
\hline Factor & Profile & $\boldsymbol{N}$ & $\%$ \\
\hline Shareholding & Local shareholding & 31 & 29.20 \\
& International shareholding & 47 & 44.30 \\
& Mixture - local and international shareholding & 28 & 26.40 \\
& Total & 106 & 100 \\
Company & R0 - R5 million & 5 & 5.00 \\
turnover & $>$ R5 million - R50 million & 17 & 16.80 \\
& $>$ R50 million - R200 million & 25 & 24.70 \\
& $>$ R200 million & 54 & 53.50 \\
& Total & 101 & 100 \\
\hline \multirow{3}{*}{ Employees } & 1-20 employees & 2 & 1.90 \\
& 21-50 employees & 10 & 9.30 \\
& 51-200 employees & 40 & 37.40 \\
& $>$ 200 employees & 55 & 51.40 \\
& Total & 107 & 100 \\
\hline Province & Gauteng & 49 & 46.70 \\
& KwaZulu-Natal & 10 & 9.50 \\
& Eastern Cape & 34 & 32.40 \\
& Western Cape & 12 & 11.40 \\
& Total & 105 & 100 \\
\hline & CEO/Senior manager & 51 & 52.00 \\
& Technical manager & 10 & 10.20 \\
& Administrative Procurement manager & 37 & 37.80 \\
& Total & 98 & 100 \\
\hline
\end{tabular}

were from the KwaZulu-Natal Automotive cluster and 12 $(11.4 \%)$ were from the Western Cape cluster.

A good spread with regard to the position of the respondents was obtained from 98 respondents (Table 4). Fifty one (52\%) of the respondents held CEO or senior management positions whilst $37(37.8 \%)$ of them were administrative or procurement managers and $10(10.2 \%)$ were technical managers.

In general a good representation was obtained of the South African automotive component manufacturers who are Tier 1 suppliers to automotive equipment manufacturers.

\section{Analysis and findings}

In order to test the importance of trust in the South African automotive supply chain and its directional correlation towards relationship value, a linear regression model was conducted. The description below outlines the steps and analysis.

Firstly, principal component analyses were conducted, using principal component extraction and varimax rotation, to determine the unidimensionality of each of the constructs trust and relationship value. The Kaiser-Meyer-Olkin Measure of Sampling Adequacy was 0.750 and 0.714 for trust and relationship value respectively, and the Bartlett's Test of Sphericity was significant $(p<0.001)$ for both constructs, indicating that factor analysis was appropriate.

The analyses confirmed unidimensionality for both trust and relationship value, as the analyses identified only one factor in each case, based on the eigenvalue criterion (eigenvalue
TABLE 5: Descriptive statistics: Trust and relationship value.

\begin{tabular}{lcc}
\hline Construct & Trust & Relationship value \\
\hline$N$ & 114 & 114 \\
Mean & 5.8655 & 5.7412 \\
Median & 6 & 5.6667 \\
Std. Deviation & 0.92885 & 0.86078 \\
Skewness & -0.86 & -0.137 \\
Kurtosis & 1.127 & -0.527 \\
Minimum & 2.33 & 3.67 \\
Maximum & 7 & 7 \\
\hline
\end{tabular}

TABLE 6: Regression model.

\begin{tabular}{lc}
\hline Regression model & Values \\
\hline Standardised Beta & $0.751^{*}$ \\
Trust ( $p$ value) & - \\
$F$ value & $144.473^{*}$ \\
$R$ Square & 0.563 \\
$R$ square Adjusted & 0.559 \\
$*, p<0.01$ &
\end{tabular}

greater than 1). The factor loadings of trust and relationship value are shown in Table 5, and the single factors explain $85.8 \%$ and $73.3 \%$ of the variance respectively.

Using a cronbach alpha, the internal consistency (reliability) for trust and relationship value was found to be 0.917 and 0.812 respectively. As both these values are above the acknowledged threshold of 0.7, they were deemed satisfactory.

Factor based scores were subsequently calculated as the mean score of the variables included in each factor.

The descriptive statistics for trust and relationship value reveals that the standard deviations are similar. The mean scores of these constructs were both higher than 5: Trust $($ mean $=5.8655)$, and relationship value $($ mean $=5.7412)$ indicated high levels of trust and relationship value. The skewness values (trust 0.860 and relationship value -0.137) and kurtosis values (trust 1.127 and relationship value -0.527) for the two constructs do not show deviations from normality.

Linear regression is used to evaluate the directional relationship between the independent variable (trust) with the dependent variable (relationship value). The regression results are tabled in Table 6 .

The regression model reveals that trust is a strong positive statistical significant predictor, at the $1 \%$ of statistical significance, of relationship value.

Based on the above findings the conclusions will be formulated in the next section followed by recommendations to the South African automotive supply chain.

\section{Conclusion and recommendations}

This paper provides more insight into the role of trust in the South African automotive supply chain. The paper revealed 
that there is a high regard for trust in the South African automotive supply chain, specifically between the first and second tier suppliers, who are component manufacturers, as there is a strong correlation between trust and relationship value.

The continuous fostering of value through the collaborative relationships proves to be beneficial for automotive component suppliers. As the automotive industry is characterised by high levels of complexity and, therefore, a higher level of trust in a trust centric relationship is required between Tier 1 (customer) and Tier 2 suppliers. In line with the findings and recommendations of Ambe (2014:50) it is recommended that the automotive industry constantly seek ways to optimise effectiveness and competitive advantage in this complex environment. This can be achieved through collaborative partnerships, fostered by trust. Therefore, automotive component suppliers must seek for ways to foster and maintain trust centric relationships. This will result in value-adding results and sustainability in the long run. The more trust that is fostered the more collaboration will be realised.

Where buying organisations find that there is a lack of trust, between them and their strategic suppliers, they must either find a trustworthy supplier in terms of reliability and culture and philosophy (Bowersox et al. 2012:354) or work with the supplier to develop a trusting relationship. A trusting relationship can be fostered by investing time and energy to secure successful long term exchange by interaction, knowledge and innovation sharing (Saban \& Luchs 2011:52). Saban and Luchs (2011:50-51) also provide guidelines on implementing favourable conditions as a strategy to foster trust. A starting point is to create an organisational culture of trust, followed by an assessment process to determine the levels of trust. A custom made model of trust should be chosen and implemented, followed by the management and control of the trust model to ensure that it is imbedded in the organisation.

It should also be noted that the automotive industry and supply chains in the industry (also in South Africa) are characterised by a cultural diversity resulting from its origin. Therefore, it is important to introduce strategies conducive for the different cultures such as Japanese manufacturers which might differ from German and other manufacturers.

The research offers several opportunities for further research.

The current research focused only on the role of trust in the relationship between Tier 1 and Tier 2 suppliers in the South African automotive supply chain. A similar study could be undertaken at other levels (or tiers) in automotive supply chains or any other supply chains.

Further, the study investigated the role of trust from the viewpoint of the Tier 1 suppliers (customers) on their Tier 2 suppliers. It will be insightful to investigate the perceptions of Tier 2 suppliers on the trusting relationships with their customers (Tier 1 suppliers).

In conclusion, if one looks at the contribution of the automotive industry to manufacturing and the economy of South Africa it is clear that it is one of the most successful industries in the country. It competes globally and applies best practices, particularly those in supply chain management. The industry is characterised by networks of collaborative relationships on different levels. These relationships seem to be successful as they are based on trust.

\section{Acknowledgements Competing interests}

The authors declare that they have no financial or personal relationships which may have inappropriately influenced them in writing this article.

\section{Authors' contributions}

This article is based on the doctoral thesis of A.S.T. (University of South Africa). A.S.T. was therefore the main researcher and originally conceptualised the article. J.A.B-W. (University of South Africa) assisted with the final conceptualisation, additional literature research and presentation of the article. A consultant, Dr Marthi Pohl, assisted with additional statistical data analysis and interpretation.

\section{References}

Akrout, W. \& Akrout, H., 2011, 'Trust in B-to-B: Toward a dynamic and integrative approach', Recherche et Applications en Marketing 26(1), 1-21. http://dx.doi. org/10.1177/205157071102600101

Ambe, I.M., 2014, 'Determining supply chain practices of vehicle manufacturers in South Africa', Journal of Contemporary Management 11, 47-61.

Ambe, I.M. \& Badenhorst-Weiss, J.A., 2011, 'South African automotive industry: Trends and challenges in the supply chain', Journal of contemporary management $8,337-362$

Ambe, I.M. \& Badenhorst-Weiss, J.A., 2013, 'Challenges of locally manufacturer vehicle supply chains in South Africa', Journal of Transport and Supply Chain Management 7(1), 1-8. http://dx.doi.org/10.4102/jtscm.v7i1.100

AIEC, 2014, Automotive export manual 2014. Zest (Pty) Ltd., Pretoria.

AIEC, 2015, Automotive export manual 2015. Zest (Pty) Ltd., Pretoria.

Barnes, J. \& Black, A., 2013, 'The motor industry development programme 1995-2012 - What have we learned?', paper presented at the Proceedings of International Conference on Manufacturing Led Growth for Employment and Equity, Johannesburg, 20-21 May, 2013, pp. 57-183.

Bowersox, D.J., Closs, D.J., Cooper, M.B. \& Bowersox, J.C., 2012, Supply chain logistics management, 4th edn., McGraw-Hill, New York.

Çerri, S., 2012, 'Exploring factor affecting trust and relationship quality in a supply chain context', Journal of Business Studies 4, 79-90.

CSCMP, 2015, Terms and Glossary, Council for Supply Chain Management Professionals, viewed 2 July 2015, from http://www.cscmp.org

Drake, M.J. \& Schlachter, J.T., 2008, 'A virtue-ethics analysis of supply chain collaboration', Journal of Business Ethics 82, 851-864. http://dx.doi.org/10.1007/ s10551-007-9597-8

Ebrahim-Khanjari, N., Hopp, W. \& Iravani, S.M.R., 2012, 'Trust and information sharing in supply chains', Production and Operations Management 21(3), 444-464. http:// dx.doi.org/10.1111/j.1937-5956.2011.01284.x

Eggert, A., Ulaga, W. \& Schultz, F., 2006, 'Value creation in the relationship life cycle: A quasi-longitudinal analysis', Industrial Marketing Management 35, 20-27. http:// dx.doi.org/10.1016/j.indmarman.2005.07.003

Fawcett, S.E., Magnan, G.M. \& Williams, A.J., 2004, 'Supply chain trust is within your grasp', Supply Chain Management Review 8(2), 20-26.

Geykens, I. \& Steenkamp, J.B., 1995, 'An investigation into the joint effects of trust and interdependence on relationship commitment', paper presented at the Proceedings of the 24th Annual Conference of the European Marketing Academy ESSEC, Cergy-Ponicise, France, 16-19 May, 1995, pp. 351-371. 
Gounaris, S.P., 2005, 'Trust and commitment influences on customer retention: Insights from business-to-business services', Journal of Business Research 58 , 126-140. http://dx.doi.org/10.1016/S0148-2963(03)00122-X

Jacobs, F.R., Chase, R.B. \& Aquilano, N.J., 2009, Operations and supply management, 12th edn., McGraw-Hill, New York.

Lamprecht, N., Rudansky-Kloppers, S. \& Strydom, J.W., 2011, 'South African automotive policy intervention (1924-2008): The case of an intelligently designed automotive support structure', Journal of Contemporary Management 8, 54-75.

Li, L., Ford, J.B., Zhai, X. \& Xu, L., 2012, 'Relational benefits and manufacturer satisfaction: An empirical study of logistics service in supply chain', Internationa Journal of Production Research 50(19), 5445-5459. http://dx.doi.org/10.1080/00 207543.2011.636388

Morgan, R.M. \& Hunt, S.D., 1994, 'The commitment - Trust theory of relationship marketing', Journal of Marketing 58(3), 20-38. http://dx.doi.org/10.2307/1252308

Naude, M.J. \& Badenhorst-Weiss, J.A., 2012, 'Supplier-customer relationships: Weaknesses in South African automotive supply chains', Journal of Transport and Supply Chain Management 6(1), 91-106. http://dx.doi.org/10.4102/jtscm.v6i1.33

Saban, K.A. \& Luchs, R., 2011, 'The benefits of governing with a trust-centric strategy', Journal of Leadership, Accountability and Ethics 8(3), 43-55.

Sako, M., 2006, 'Does trust improve business performance?', in R.M. Kramer (ed.), Organisational trust: A reader, pp. 267-294, Oxford, New York.
Swink, M., Melnyk, S.A., Cooper, M.B. \& Hartley, J.L., 2011, Managing operations across the supply chain, McGraw-Hill, New York.

Theron, E., Terblanche, N. \& Boshoff, C., 2011, 'The antecedents of trust in businessto-business financial services', Journal of Business-to-business Marketing 18, 188-213. http://dx.doi.org/10.1080/1051712X.2010.499837

Thomas, R. \& Skinner, L., 2010, 'Total trust and trust asymmetry: Does trust need to be equally distributed in interfirm relationships?', Journal of Relationship Marketing 9, 43-53. http://dx.doi.org/10.1080/15332660903551875

Tolmay, A., 2012, 'Developing a relationship value model for the South African business to business automotive supply chain', Unpublished Doctor in Busines Leadership thesis, University of South Africa, Pretoria.

Uslaner, E.M., 2002, The moral foundations of trust, Cambridge University Press, Cambridge.

Uslaner, E.M., 2013, 'Trust and corruption revisited: How and why trust and corruption shape each other', Quality \& Quantity 47, 3603-3608. http://dx.doi.org/10.1007/ s11135-012-9742-z

Vieira, L.M., Paiva, E.L., Finger, A.B. \& Teixeira, R., 2013, 'Trust and supplierbuyer relationships: An empirical analysis', BAR, Rio De Janeiro 10(3/2), 263-280.

Wisner, J.L., Tan, K-C. \& Leong, G.K., 2016, Principles of supply chain management: A balanced approach, Cengage Learning, Boston. 